\title{
Characteristics of PrekotAC as Formulated Filter Aids and Its Performance to Adsorb Volatile Organic Compound
}

\author{
N. Masdianal , M. Rashid ${ }^{\text {* }}$, S. Hajarl , M.R. Ammar ${ }^{2}$ \\ ${ }^{1}$ Air Resources Research Laboratory, Malaysian Japan International Institute Technology, 54100 UTM Kuala Lumpur \\ ${ }^{2}$ AMR Environmental Sdn. Bhd., Taman Sri Pulai Perdana, 81110 Johor Bahru, Malaysia \\ *rashidyusof.kl@utm.my
}

\begin{abstract}
The characteristics of a formulated filter aids material known as PrekotAC which is a combination of an adsorbent, activated carbon with a pre-coating material was investigated in this study. PrekotAC, was formulated into two different weight ratios of 5:95 and 10:90 respectively. The relationship between the adsorption properties and the characteristics of the formulated materials in terms of its particle size distribution, particle density, bulk density, moisture content as well as its BET surface area was investigated. A specific amount of $100 \mathrm{mg}$ of formulated filter aids was placed in a fixed glass tube and subjected to a given concentration of toluene at the temperature of $25^{\circ} \mathrm{C}$ and $1.01 \mathrm{pm}$ gas flow rate. The adsorption properties of each filter aids material was tested under various time where the amount of toluene adsorbed by the filter aids was analysed using gas chromatography equipped with flame ionization detector (GC-FID). The ability of the formulated filter aids to adsorb toluene was presented and discussed in this paper.
\end{abstract}

\section{Introduction}

The environmental issue has become a major subject in the last few decades, affecting developed as well as those of developing nations. For an example, air pollution emission from waste incineration such as acid gases, particulate matter, heavy metals and volatile organic compounds (VOCs) are released into the atmosphere [1]. Organic compounds that include dioxin-furan is recognized to be one of the most potent pollutant resulted through post-combustion in incineration process.

Organic compounds are carbon-based compounds derived from many sources. It (author) was reported that $37 \%$ of total VOCs emissions comes from coal-fired power plants [2]. These emissions are of public concern especially VOCs considered as toxic chemicals causing severe health problems [3]. Prolonged exposure to VOCs has been shown to induce eye and throat irritation, damage to the liver and central nervous system as well as increase relative rates of leukemia and lymphoma [4]. Therefore, the removal of VOCs from a flue gas stream is of significant interest. There are five methods of removing VOCs from contaminated gas stream and these are adsorption, absorption, condensation, incineration, and biofiltration. However, adsorption seems to be the most commonly used in this case [5].

Activated carbon has been extensively used in variety of environmental applications as adsorbent in gas purification, solvent recovery and waste water treatment, due to its large surface area and high adsorption capacity [6]. Activated carbon has been used as an adsorbent in fabric filtration system which is commonly found in most waste incineration plant. In addition, filter aids is also applied to coat a layer of inert material onto each of the filter bag acting as a barrier for protection as well as to allow a uniform air flow passing through the filter media [7].

Thus, the aim of the present study is to investigate the characteristics of a formulated filter aids material which is a combination of activated carbon and precoating agent. In addition, the ability of the formulated filter aids to adsorb VOCs is presented and discussed in this paper.

\section{Materials}

Table 1 presents the specifications of the two main powder materials used in this study, which are activated carbon and PreKot ${ }^{\mathrm{TM}}$. The toluene solution of $99.99 \%$ purity (Merck) was used in the adsorption study.

Table 1. Specification of the materials used in the study.

\begin{tabular}{|c|c|}
\hline Activated carbon & PreKot $^{\text {TM }}$ \\
\hline Colour: black & Colour: snowy white \\
\hline Origin: coal based & Origin: silica based \\
\hline Surface area: $1094.96 \%$ & Surface area: $2.52 \%$ \\
\hline Moisture content:23.39\% & Moisture content: $0.73 \%$ \\
\hline
\end{tabular}

\footnotetext{
* Corresponding author: rashidyusof.kl@utm.my
} 


\section{Experimental methods}

\subsection{Formulation of the Filter Aids}

PreKot ${ }^{\mathrm{TM}}$ and activated carbon were mixed into 5:95 and 10:90 of two different weight percentage respectively. Initially before formulation, the raw materials were dried in an oven (Memmert, Model UNB 200) for 24 hours at $110^{\circ} \mathrm{C}$. Then, the properties of the formulated filter aids designated as PrekotAC were characterized in term of its surface area (BET), particle size distribution, particle density, bulk density and moisture content.

\subsection{Material characterization}

Particle size distribution was determined using a particulate sizer (Malvern Mastersizer 2000). The measurement was repeated two times and the average particle size distribution was taken by the software. The determination of the particle density of the material was measured using a gas pycnometer (Micromeritics AccuPyc II 1340), using nitrogen as a carrier gas. While the bulk density of the sample was measured based on the equation (1) where the sample was filled and compacted in a pre-weighed $10 \mathrm{~mL}$ standard measuring cylinder up to the specific volume and re-weighed in order to determine the bulk density [8].

$$
\text { Bulk density }=W m / V c
$$

Where;

$W_{m}=$ weight of the dried material $(\mathrm{g})$

$V_{c}=$ volume of the cylinder $(10 \mathrm{~mL})$

The specific surface area (SBET) was estimated by the BET equation (2). The porous structure of the sample was characterized by $\mathrm{N}_{2}$ adsorption isotherms at $77 \mathrm{~K}$ using TriStar II 3020 V1.04. The specific surface area is an important characteristic in determining the chemical and physical interaction of the adsorbent and its surroundings. This is due to the fact that adsorption take place at the surface of particles.

$(v / v m)=C\left(P / P_{0}\right) /\left\{[1-(P / P 0)]\left[1+(c-1)\left(P / P_{0}\right)\right]\right\}$

Where;

$\quad=$ volume of gas adsorbed per unit weight of material at pressure $P$

vm = volume of gas adsorbed for monolayer coverage

$\left(\mathrm{P} / \mathrm{P}_{0}\right)=$ partial pressure of the gaseous adsorbate

$\mathrm{C}=$ constant

The moisture content of the formulated sample was determined based on a standard measurement (ASTM D2867-09) [9]. Approximately $2 \mathrm{~g}$ of the formulated sample was placed in a pre-weighed petri dish and exposed to the atmosphere for a few days. Then the sample was dried in an oven at $110^{\circ} \mathrm{C}$ for 24 hours to discard the moisture content in the sample. Later, the sample was removed from the oven and cooled to an ambient temperature in a desiccator before it was re- weighed. The experimental procedure was repeated twice and the average moisture content was taken. The moisture content of the sample was then calculated using equation (3) as written below.

$$
\text { Moisture content }(\%)=\left[\left(S_{i^{-}} S_{a}\right) /\left(S_{i^{-}} W p\right)\right] \times 100
$$

Where;

$\mathrm{Wp}=$ weight of the petri dish $(\mathrm{g})$,

$\mathrm{S}_{\mathrm{i}} \quad=$ initial weight of petri dish with sample $(\mathrm{g})$

$\mathrm{S}_{\mathrm{a}} \quad=$ weight of petri dish with sample after $\operatorname{drying}(\mathrm{g})$

\subsection{Adsorption Study}

\subsubsection{Sample preparation}

Figure 1 shows the schematic diagram of the adsorption experimental set up which consist of toluene solution, temperature sensor, adsorbent packed -glass (formulated filter aid), flowmeter and vacuum pump. Stopcock was used to control the toluene's flow during adsorbent exchange. Prior to start any experiment, all samples of formulated filter aids were dried for 24 hours in oven at $110^{\circ} \mathrm{C}$ to remove all adsorbed gases and moisture content [10]. A fixed glass with inside diameter of $4 \mathrm{~mm}$, outside diameter $8 \mathrm{~mm}$ and total length $60 \mathrm{~mm}$ was used for dynamic study. A $100 \mathrm{mg}$ of adsorbents were filled and compacted in a glass enclosed with glass wool and covered with a cap. After packaging, all prepared samples were stored in desiccator prior to use for sampling.

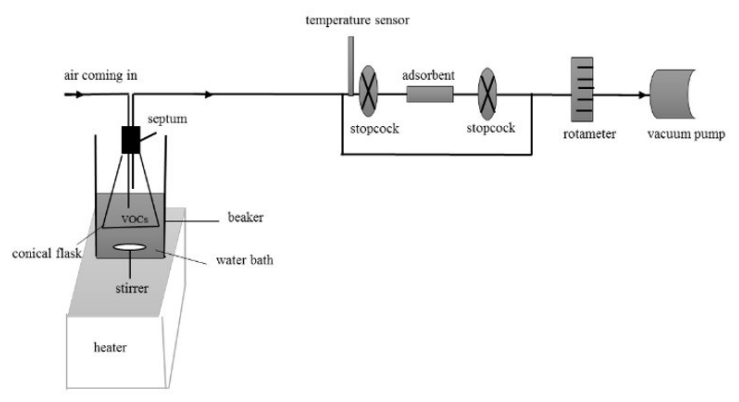

Fig. 1. Schematic diagram of experimental set-up

\subsubsection{Adsorption Test}

For each set of experiment, $100 \mathrm{~mL}$ of toluene with $99.99 \%$ concentration was adsorbed by $100 \mathrm{mg}$ amount of total adsorbent dose at $25^{\circ} \mathrm{C}$ with $11 \mathrm{pm}$ flowrate. Initially, $100 \mathrm{mg}$ adsorbent dose were packed in glass and placed in the adsorption system (Figure 1). The toluene's solution was bubbled and pumped through the system towards adsorbent. A water bath was used to keep the toluene solution in a desired constant temperature $\left(50^{\circ} \mathrm{C}\right)$. Before the start of experimental run, toluene gas were freely pumped throughout the system for 10 minutes to ensure the gas distribute properly across the system. Sampling was done continuously and the effluent gas was collected at time intervals between 5 and 40 minutes and its concentration was determined by using gas 
chromatography equipped with flame ionization detector (GC-FID).

\subsubsection{Analytical method}

The sample was analysed using GC-FID with capillary column. FID detects analytes by measuring an electrical current generated by electrons from burning carbon particles in the sample. The adsorbed toluene was analysed using the NIOSH method [11]. The sample was desorbed in $2 \mathrm{~mL}$ of dichloromethane and allowed to stand with occasional shaking for 30 minutes [12]. A $1 \mu \mathrm{L}$ of sample extract was used for one injection. Each sample was injected twice and the average result was calculated. The oven temperature was set initially at $40^{\circ} \mathrm{C}$ for 3 minutes and then raised to $88^{\circ} \mathrm{C}$ per min. Both the auxiliary and detector temperatures were set at $250^{\circ} \mathrm{C}$. The standard of toluene solution was used for quantification of the compounds.

\section{Results and discussions}

\subsection{Material characterization}

\subsubsection{Characteristics in terms of particle size distribution}

Figure 1 and 2 presents the particle size distribution of raw materials and formulated filter aids materials. Figure 1 showed that activated carbon has a finer particle size distribution compared to PreKot ${ }^{\mathrm{TM}}$. This results were in a good agreement with the previous study by Hajar et al. (2013) and Hajar et al. (2015) where it was reported that activated carbon has finer particle size distribution compared to PreKot ${ }^{\mathrm{TM}}[7,13]$. By having a small particle material, it is good for adsorption purpose because as the particle size decreases, the degree of contact area between the particles increase and lead to a better adsorption properties.

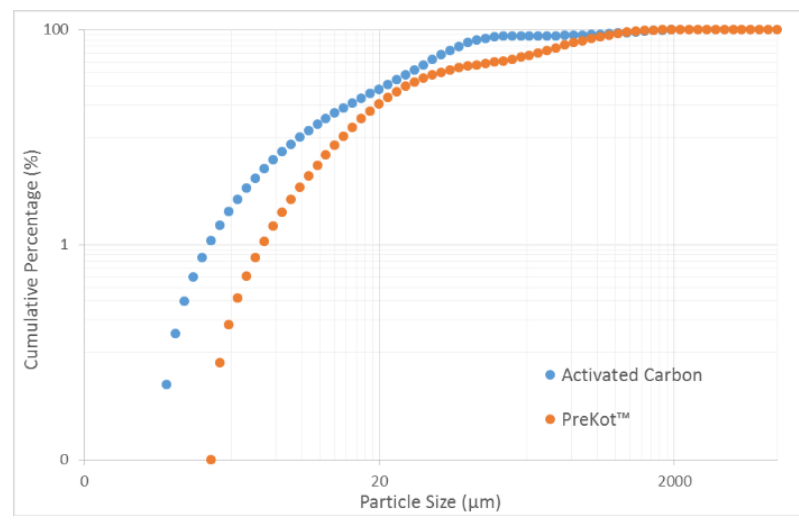

Fig. 1. Particle size distribution of raw materials

As shown in Figure 2, the formulated filter aids materials (PrekotAC 5:95 and PrekotAC 10:90) fitted perfectly with the original materials which proved that it has a very well distributed particle size distribution (Figure 2). It was reported that PrekotAC helps to improve the filtration performance by reducing the pressure drop across the filter cake as well as increases the filtration efficiency [7]. In addition, having a well distributed particle size distribution, PrekotAC could also be used as flue gas cleaning agent where it can be applied as a two in one filter aids material, pre-coating material as well as an adsorbent.

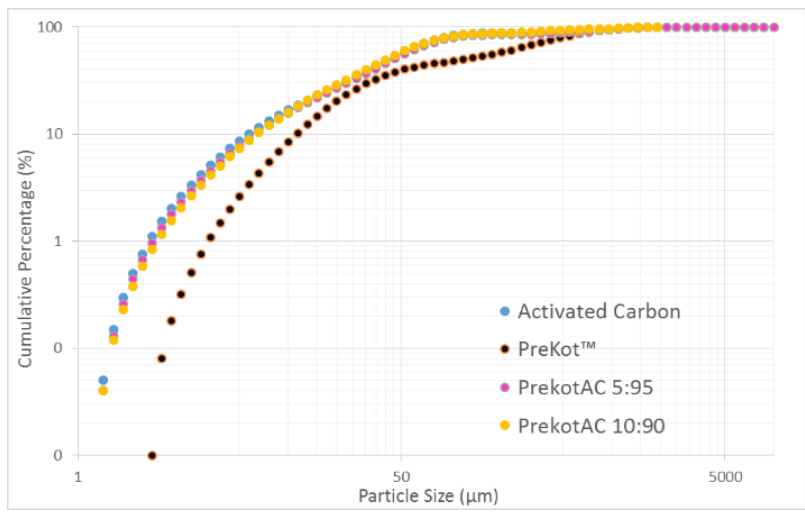

Fig. 2. Particle size distribution of raw materials and formulated samples

\subsubsection{Characteristics in terms of bulk density and particle density}

Figure 3 illustrates the results on the bulk density and particle density of the filter aids materials where it was found that activated carbon gives the highest while PreKot $^{\mathrm{TM}}$ has the lowest density. PrekotAC laid nicely between their original materials with PrekotAC 5:95 showed slightly higher in bulk density $\left(0.64 \mathrm{~g} / \mathrm{cm}^{3}\right)$ and particle density $\left(1.48 \mathrm{~g} / \mathrm{cm}^{3}\right)$ compared to PrekotAC 10:90. There is not much different in bulk density and particle density for the formulated filter aids because of the close ratio of formulation.

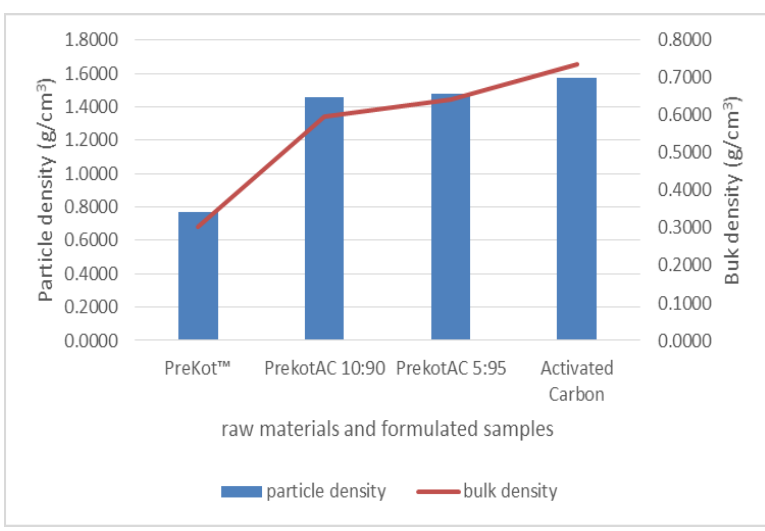

Fig. 3. Bulk density and particle density of raw materials and formulated samples

However, from the results, it showed that as the amount of PreKot ${ }^{\mathrm{TM}}$ in the formulation increases, the bulk and particle density decrease which explained the linear trend relationship of bulk density and particle density with the addition of PreKot ${ }^{\mathrm{TM}}$. It also showed that PreKot ${ }^{\mathrm{TM}}$ plays an important role in reducing bulk density and enhancing the porosity of the material for better filtration due to its particle characteristics [7]. 
By applying a filter aids material with a high porosity helps in reducing pressure drop across filter cake and also good for adsorption purpose. This is because, greater porosity materials lead to better roughness and larger specific surface area.

\subsubsection{Characteristics in terms of BET surface area}

Specific surface area is a fundamental measurement in the field of fine particle characterization especially in adsorption process. Specific surface area is defined as the surface area per unit mass of sample. Figure 4 showed a BET surface area of raw materials and formulated samples which showed that activated carbon has the largest while PreKot ${ }^{\mathrm{TM}}$ has the smallest surface area with $1094.96 \mathrm{~m}^{2} / \mathrm{g}$ and $2.52 \mathrm{~m}^{2} / \mathrm{g}$, respectively.

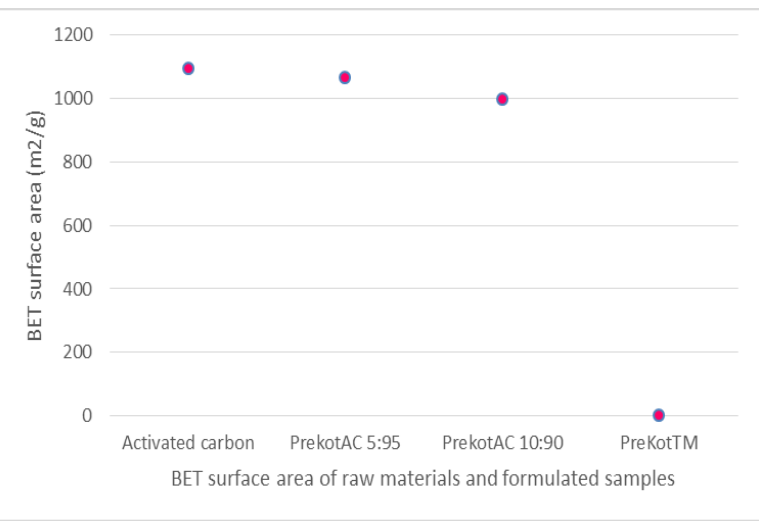

Fig. 4. BET surface area of raw materials and formulated samples

As shown in the figure, surface area consistently increases with the decreasing amount of PreKot ${ }^{\mathrm{TM}}$ with PrekotAC 5:95 gives higher surface area compared to PrekotAC 10:90. Both formulated filter aids have high surface area which is $1066.064 \mathrm{~m}^{2} / \mathrm{g}$ (PrekotAC 5:95) and $999.8710 \mathrm{~m}^{2} / \mathrm{g}$ (PrekotAC 10:90) where slightly lower than activated carbon alone. The large surface area accounts for the highly effective adsorptive characteristics.

\subsubsection{Characteristics in term of moisture content}

Figure 5 presents the moisture content of the raw materials and formulated samples which showed that activated carbon has the highest while PreKot ${ }^{\mathrm{TM}}$ has the lowest moisture content with $23.39 \%$ and $0.73 \%$, respectively. The formulated PrekotAC were consistent in term of their moisture content where PrekotAC 5:95 $(22.60 \%)$ presents slightly higher moisture content compared to PrekotAC 10:90 (22.27\%). The difference in moisture content due to the addition of the different amout of PreKot ${ }^{\mathrm{TM}}$. It was found that the addition of PreKot ${ }^{\mathrm{TM}}$ into the formulation helps to reduce the moisture content which is perquisite for adsorption purpose.

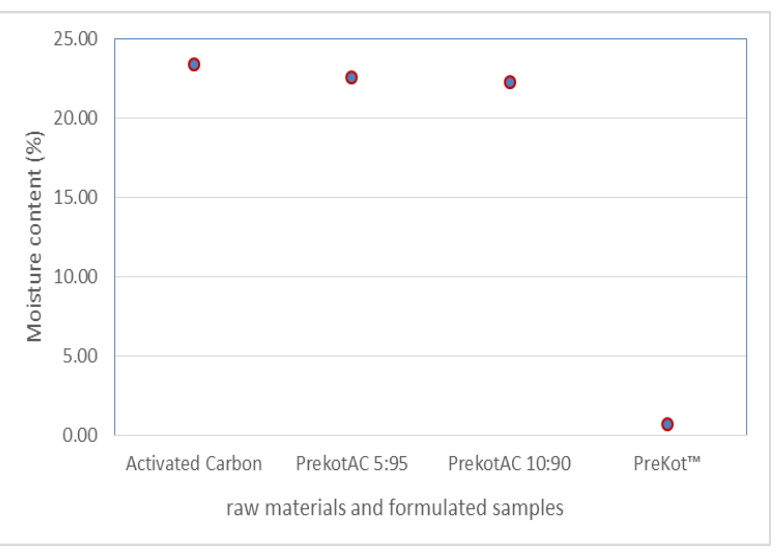

Fig. 5. Moisture content of raw materials and formulated samples

Moisture content is an important parameter since it directly influences the adsorption performance. According to Farzad et al, presence of water or moisture, trapped in activated carbon pores could lead to decrease in the amount of methane adsorption [14]. Therefore, low existence of moisture in the formulated material is better for adsorption process and indicates a good filter aids property [7]. However, the application of PrekotAC as a filter aids and flue gas cleaning agent may not be influence by moisture content since the operation occur in hot environment $\left(\sim 200^{\circ} \mathrm{C}\right)$ such as in incineration plant where high temperature will evaporate the moisture content exist in the material, thus maintained the performance as an adsorbent.

\subsection{Toluene adsorption}

\subsubsection{Comparison of adsorption performance between raw materials and formulated samples}

Figure 6 shows the total toluene adsorbed in $100 \mathrm{mg}$ of filter aids materials under four different time duration of $5,10,30$, and 40 minutes. Results showed that activated carbon gives the highest amount of toluene adsorbed $(331 \mu \mathrm{g})$ at 5 minutes compared to the other materials. It was also found that as time of adsorption increase, the amount of toluene adsorbed also increased. However, PreKot ${ }^{\mathrm{TM}}$ do not give a good result in adsorption where it was observed that the amount of toluene adsorbed decreased by the time of adsorption process. It showed that $\operatorname{PreKot}^{\mathrm{TM}}$ did not give much contribution on adsorption process compared to the other filter aids materials. 


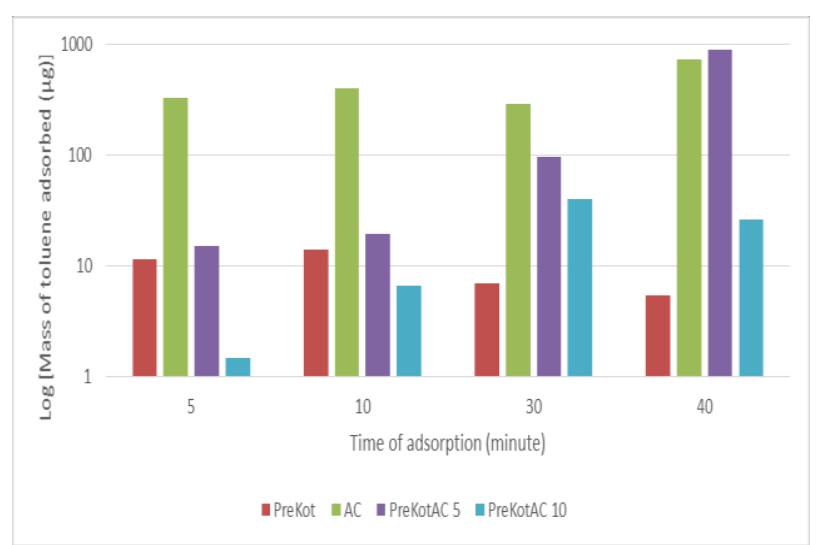

Fig. 6. Toluene's adsorption by raw materials and formulated samples at various time

As shown in the figure, PrekoatAC showed high adsorption of toluene, proving that the combination of activated carbon and PreKot ${ }^{\mathrm{TM}}$ still give a good adsorption properties. This can be explained by the fact that high number of surface area of formulated samples contribute to adsorb higher amount of VOC [14]. As the time increases, toluene loading volume increases until the saturation rate achieved. In this study, both formulated filter aids have a good potential as an effective adsorbent in fabric filter for flue gas cleaning purpose.

\section{Conclusions}

The formulated filter aids material PrekotAC showed a promising characteristic as an adsorbent for VOCs in fabric filter system. Having a small particle size with a large surface area will contribute to a better adsorption properties in a flue gas cleaning process. In addition, the improvement in terms of particle and bulk density would increase the porosity of material and maintain the adsorption performance of formulated material due to the higher surface area. It was also found that the combination of activated carbon and PreKot ${ }^{\mathrm{TM}}$ helps to reduce the moisture content in the formulated material. Results showed that PrekotAC has the capability to be applied as an adsorption for volatile organic compound (VOC) during flue gas cleaning process.

The authors gratefully acknowledge supervisor and Air Resource, MJIIT's team for their appreciable support.

\section{References}

1. X. Su, L. Zhang, Y. Xiao, M. Sun, X. Gao, J. Su, J., evaluation of a flue gas cleaning system of a circulating fluidized bed incineration power plant by the analysis of pollutant emissions, Powder Technology, 286, 9-15 (2015)

2. D. Prada-rodr, E. Fern, distribution of volatile organic compounds during the combustion process in coal-fired power stations, 35, 58235831 (2001)
3. H. Zaitan, M. Manero, H. Valdés, L. Chimie De, D. Matière, C. Lcmc, M. Ben, application of high silica zeolite ZSM-5 in a hybrid treatment process based on sequential adsorption and ozonation for VOCs elimination, JES. 1-10 (2015)

4. P. Irigaray, J. A. Newby, R. R. Clapp, L. Hardell, V. Howard, L. Montagnier, D. Belpomme, lifestyle-related factors and environmental agents causing cancer: An overview. 61, 640658 (2007)

5. T. Cheng, Y. Jiang, Y. Zhang, S. Liu, prediction of breakthrough curves for adsorption on activated carbon fibers in a fixed bed, Carbon, 42, 3081-3085 (2004)

6. K. P. Bhabendra, N. K. Sandle, effect of different oxidizing agent treatments on the surface properties of activated carbon, Carbon , 37, 1323-1332 (1998)

7. S. Hajar, M. Rashid, A. Nurnadia, M. R. Ammar, formulation of a new pre-coating material for fabric filtration in air filtration system, MalaysiaJapan International Institute of Technology (MJIIT)- Japanese University Consortium (JUC) Joint International Symposium. $6^{\text {th }}-8^{\text {th }}$ November. Hiratsuka, Japan (2013)

8. S. K. Theydan, M. J. Ahmed, optimization of preparation conditions for activated carbons from date stones using response surface methodology, 224, 101-106 (2012)

9. ASTM D2867, standard test method for moisture content in activated carbon (2014)

10. F. Zeinali, A. A. Ghoreyshi, G. D. Najafpour, adsorption of dichloromethane from aqueous phase using granular activated carbon: Isotherm and breakthrough curve measurements, MiddleEast Journal of Scientific Research, 5, 191-198 (2010)

11. National Institute for Occupational Safety and Health (NIOSH), manual of analytical methods, fourth ed. hydrocarbons, aromatic (1994)

12. E. M. Martins, G. Arbilla, G. F. Bauerfeldt,M. de Paula, atmospheric levels of aldehydes and BTEX and their relationship with vehicular fleet changes in Rio de Janeiro urban area. Chemosphere, 67, 2096-2103 (2007)

13. S. Hajar, M. Rashid, A. Nurnadia, M. R. Ammar, the characteristics of a formulated filter aids for fabric filters, Powder Technology, 283, 315-320 (2015)

14. S. Farzad, V. Taghikhani, C. Ghotbi, B. Aminshahidi, L. E. Nemati, experimental and theoretical study of the effect of moisture on methane adsorption and desorption by activated carbon at $273.5 \mathrm{~K}$, Journal of Natural Gas Chemistry, 16, 22-30 (2007) 